Print ISSN: 2233-4165 / Online ISSN: 2233-5382

doi:http://dx.doi.org/10.13106/ijidb.2018.vol9.no12.63.

\title{
The Study on the e-Service Quality Factors in m-Shopping Mall App based
} on the Kano Model

\section{카노 모형을 이용한 모바일 쇼핑몰 앱의 서비스 품질 요인 분석에 관한 연구*}

\author{
Sang-Oh Kim(김상오) $)^{* *}$, Sun-Hee Youn(윤선희) $)^{* * *}$, Myung-Jin Lee(이명진) $)^{* * * *}$
}

Received: November 26, 2018. Revised: December 01, 2018. Accepted: December 05, 2018.

\section{Abstract}

Purpose - In this study, it is classified the service quality dimension of mobile shopping app using Kano model. In addition, it is evaluated quality factors suitable for strategic management from the viewpoint of service provider through mobile application through binary dimension analysis.

Research design, data, and methodology - In this study, seven quality dimensions such as information quality, reliability, immediacy, convenience, design, security and customer service were derived through related studies to make binary shopping quality app quality measurement. 37 sub-variables were set by each quality dimensions. Each questionnaire was composed of positive and negative items like Kano's proposed method, and the satisfaction coefficient suggested by Timko(1993) was examined to understand the influence of each factors on customer satisfaction.

Results - As a result of research, shopping app users perceived unity quality factor in most items of service quality dimension such as information quality, reliability, immediacy, convenience and customer service. In addition, the satisfaction coefficient showed a good impression, quick response of the result, fast delivery, and the unsatisfactory coefficient showed more interest in personal information such as payment method safety, and transaction security. As a result of research, shopping app users perceived unity quality factor in most items of service quality dimension such as information quality, reliability, immediacy, convenience and customer service. And, in information quality, the information overload was classified as an apathetic quality component, while the related information provision belonged to an attractive quality component. In reliability quality, customized service provision was classified as an attractive quality component. In instant connectivity, the quality of the connection during transport was classified as an attractive quality component. In convenience quality, access to product information was classified as a one-way quality component. All components of designs quality were classified as attractive quality components, and in security quality, all of their components were all classified as one quality component. Lastly, in customer service, they components were all classified as a single quality component. In addition, the satisfaction coefficient showed a good impression, quick response of the result, fast delivery, and the unsatisfactory coefficient showed more interest in personal information such as payment method safety, and transaction security.

Conclusion - In the online service environment, which is difficult to differentiate in terms of upward upgrading only by technological implementation and function, the results of this study can be suggested as a differentiating factor for major channels with customers rather than improve the brand image.

Keywords: Kano Model, App Quality, Mobile Shopping Mall App.

JEL Classifications: M11, M15, M19.

* This paper has been studied by supporting the scholarships of Semyung University in 2018.

** First Author, Professor of Department of Electronic Commerce, Semyung University, Korea. E-mail: sokim@semyung.ac.kr,

*** Adjunct Professor of Department of Business Administration, Hanyang University, Korea. E-mail: younsh365@gmail.com

**** Corresponding Author, Adjunct Professor of Department of Business Administration, Soongsil University, Korea.

E-mail: myungjin@ssu.ac.kr

\section{1. 서론}

기업의 IT도입 및 인터넷 서비스 확산으로 편리성과 비용우 위 측면에서 전자상거래의 이용자가 급증하고 있다. 이에 따라 온라인 쇼핑몰 또한 물류비용, 광고비용, 판매비용 등의 경쟁 력을 통해 급격한 성장과 발전을 이루고 있다(Chun \& Lim, 2012). 이러한 전자상거래는 스마트폰이라는 도구의 등장으로 새로운 국면을 맞이하였다. 스마트폰은 모바일 앱스토어라는 이동통신사를 중심으로 성장해온 모바일 비즈니스 구조가 개 방형모델로 전환되는 계기를 제공하고 있고, 개방적 혁신이라 
는 특화된 비즈니스 모델로서 새로운 시장을 창출하고 있다 (Kwon \& Park, 2015). 시장을 접근할 수 있는 스마트폰이라는 도구의 성장과 모바일 어플리케이션의 급격한 성장은 모바일 콘텐츠 시장의 성장의 기반이라 할 수 있다. 소비자는 스마트 폰을 이용하여 쇼핑몰의 상품검색에만 그치지 않고 앱(App)에 서도 상품을 구매하고 있다(Chun \& Lim, 2012). 이러한 새로 운 시장의 성장은 사업자에게 있어서 새로운 기회가 됨과 동 시에 사용자 관점에서의 서비스 품질에 대한 연구의 필요성이 대두되고 있다.

기업의 마케팅측면에서 기업의 생존과 성장의 필수적인 요 소인 서비스 품질은 오프라인시장에서 온라인 또는 스마트폰 시장으로 유통시장이 변화함에 따라 서비스 품질의 연구도 다 양하게 진행되고 있다(Zeithaml, Parasuraman, \& Malhotra, 2002; Parasuraman, Zeithaml, \& Malhotra, 2005; Han, 2016).

스마트폰 앱품질 향상과 관리를 위해 서비스 품질 척도개발 에 대한 연구들도 증가하고 있다(Shon \& Park, 2013; Han, 2016). 선행연구들을 살펴보면, 스마트폰 시장에서 서비스 품 질의 선행연구를 토대로 새로운 척도를 개발하는 방법 $(\mathrm{Kim} \&$ Oh, 2006; Lee, La, \& Song, 2009; Kim \& Kim, 2011; Han, 2016)과 기존의 오프라인과 온라인 서비스 품질연구를 모바일 시장에 적용하거나 확장하는 연구들이 있다(Roh \& Chung, 2005; Park, 2010; Lee, 2011; Han, 2016). 이러한 온라인 시 장을 기반으로 한 서비스 품질은 e-서비스 품질이라는 개념으 로 연구되어 오고 있는데, 이는 웹 사이트의 기술적 품질 차 원, 고객 만족에 영향을 주는 차원 그리고 웹사이트 서비스 품 질 차원 등 3 가지 차원에 집중되고 있다(Akinci, Atilgan-Inan, \& Aksoy, 2010).

이러한 대부분의 서비스 품질 요인에 대한 연구들의 요소들 은 일원적 인식 방법의 한계를 가지고 있다는 점에서 이원적 방식으로 품질 속성을 분류하고 우선순위를 정하기 위한 카노 모형(Kano Model)이 개발되었다. 그래서 쇼핑몰 앱에 대한 품 질 요인들도 이러한 관점에서, 동기-위생이론을 기반으로 한 이 원적 품질 분류법을 활용하여 비선형적인 방향의 연구가 필요 하다. 그러나 기존에는 쇼핑몰앱을 대상으로 카노모형을 이용한 서비스 품질 요인들에 대한 연구가 거의 이루어지지 않았다.

따라서 본 연구를 통해 카노모형을 활용하여 쇼핑몰앱의 서 비스 품질 요인을 분류함으로써 전략적 관리에 적합한 품질요 소들을 분류하고 평가하고자 한다. 특히, Kano모델은 서비스 품질을 2원적으로 분석함으로서 단순한 특정 서비스 품질의 중요성 뿐만 아니라, 소비자에게 인식되는 수준까지 파악하여 제시할 수 있다.

이를 통해, 온라인 쇼핑몰 기업들의 기본적이고 지속적인 서비스 품질 노력 수준을 유지하기 위한 노력에 있어, 보다 효 과적으로 중점 관리가 이루어져야 하는 서비스 품질 차원을 통해 차별적인 서비스 접근방안을 제시할 수 있을 것이다. 모 바일 기기로의 이용환경이 변화하고 있는 시점에, 모바일 쇼핑 앱은 더이상 웹사이트의 보완적 기능으로서가 아닌 고객과의 주 요 채널로 인식되어야 하며, 기존 경쟁사와의 경쟁에서 차별적으 로 접근할 수 있는 방안으로 활용될 수 있을 것으로 기대한다.

이를 위하여 선행연구들을 바탕으로 쇼핑몰에 대한 다양한 품질 요인들을 도출하고, 선정된 쇼핑몰의 서비스 품질 요인을 카노모형을 이용하여 5 가지 차원으로 분류하고, 각 요소들의 고객만족도에 대한 영향력을 파악하기 위하여 Timko(1993)가 제시한 만족계수를 살펴봄으로써 쇼핑몰앱의 서비스 품질 향 상을 위한 방안을 제시하는데 자료로 활용할 수 있을 것이다.

\section{2. 이론적 배경}

\section{1. 모바일 쇼핑몰 서비스 품질}

최근 모바일 시장은 2009년 아이폰을 시작으로 스마트 폰 과 테블릿 PC 등 스마트 기기의 보급이 확대되면서 이용률도 함께 증가하고 있다. 스마트폰이 보급은 기존의 $\mathrm{PC}$ 기반에서 모바일로 부상하여 비즈니스 세계에 커다란 변화를 초래하고 있다. 모바일 쇼핑(mobile shopping)은 무선인터넷을 이용하여 인터넷이라는 시공간적 구애에서 보다 자유로운 모바일 비즈 니스 환경에서 소비자가 원하는 상품과 서비스에 대한 정보를 탐색하고 구매하는 행위로 볼 수 있다. 따라서 기존 PC 기반 의 인터넷 쇼핑과의 다르게 이동성과 즉시성이라는 큰 차이점 을 지니며, 이용자가 편리한 시간과 장소에서 쇼핑이 가능하다 (Kim, 2014).

모바일 쇼핑에 대해 Siau, Lim, and Shen(2001)은 "무선 통 신 네트워크나 다른 유선 전자상거래 기술을 활용하는 모바일 장치를 통해 수행되는 새로운 형태의 전자상거래"라고 정의하 고 있다. Bang(2013)은 "모바일 기기를 이용하여 애플리케이 션이나 웹 사이트에서 시간과 장소에 구애받지 않고 언제 어 디서든지 상품을 구매할 수 있다는 것"으로 해석하였다.

카노모형을 활용한 연구의 자료수집 방법은 설문조사를 통 해 각 서비스 품질 요인의 특성을 알아보는 것이다. 이를 위해 문헌연구 방법으로 온라인 쇼핑몰 앱의 서비스 품질을 결정하 는 요인들을 도출하고 이를 바탕으로 설문지를 구성하고자 하 였으며, 주로 온라인 쇼핑몰 앱 또는 온라인으로 작동하는 기 타 앱에 관련된 선행연구를 검토하여 다음과 같은 요인들을 선정하였다.

\subsection{1. 정보성}

정보성은 상품이 품질 높은 정보를 충분히 제공해주는지에 관한 것으로써 몇몇 선행연구들에서 상품의 만족도에 정보성 이 영향을 준다고 알려져 있다. Jin and Lee(2012)는 소셜커머 스의 정보성이 이용만족도에 긍정적인 영향을 준다고 하였고, $\mathrm{Kim}$ and Yun(2012)은 SNS의 정보품질이 만족도에 긍정적 영 향을 준다고 하였으며, Lu and Lee(2014)는 모바일 메신저 앱 의 정보품질이 만족도에 긍정적 영향을 준다고 하였다. 이외에 앱 관련 서비스 품질 연구에서 여러 연구자가 정보성을 서비 스 품질을 측정하기 위한 요인으로 선정하였다(Shon \& Park, 2013; Lee, Seo, \& Song, 2016; Han, 2016; Jeon, Kim, \& Jeong, 2016).

\subsection{2. 신뢰성}

앱 서비스의 신뢰성은 서비스 제공자가 이용자에게 손해를 끼치지 않고 호의적인 서비스를 제공할 것이라는 기대를 주는 것이다. 예를 들어, 이용자 정보가 자주 유출되거나, 약속된 서비스가 제공되지 않는 앱에는 이용자들이 신뢰를 가지지 않 고 만족도가 떨어지거나 이용하지 않게 될 것이다. 이와 반대 로 이용자의 요구에 맞는 서비스를 제공하는 등 이용자와의 접점에서 좋은 인상을 준다면 이용자들이 신뢰를 가지고 만족 하게 될 것이다. 앱 관련 서비스 품질 선행연구에서는 $\mathrm{Han}$ (2016)와 Jeon et al.(2016), Shon and Park(2013) 등이 신뢰 성을 서비스 품질을 측정하기 위한 요인으로 선정하였다. 


\subsection{3. 즉시연결성}

쇼핑 앱의 즉시연결성이란 시간과 장소에 구애받지 않고 즉 각적으로 앱을 사용하여 정보를 얻고 구매를 할 수 있는 것이 다. 모바일 환경이 발달하면서 이용자들은 이동 중에도 장소에 구애받지 않고 컨텐츠나 서비스에 접속할 수 있다(Hwang \& Lee, 2011; Kim, 2012). Shin and Kim(2013)에 의하면 모바일 쇼핑의 구매자들은 즉시연결성에 대해 중요하게 생각하고 있 다. 이는 휴대성과도 관련이 있는데 Kang(2014)에 의하면 모 바일 서비스의 휴대성은 만족도에 긍정적인 영향을 미친다. 앱 관련 서비스 품질 선행연구에서 Zhang(2018), Lee and Lee (2015), Chun and $\operatorname{Lim}(2012)$ 등이 즉시연결성을 서비스 품질 을 측정하기 위한 요인으로 선정하였다.

\subsection{4. 편의성}

편의성은 고객이 서비스 이용을 결정하는데 있어 시간과 노 력을 줄이는 것으로써, 이에 대한 관심은 편리한 상품과 서비 스개발을 촉진하였으며 편의성이 제품 구매에 있어 주요 결정 요건으로 작용한다는 연구모델로 발전하게 되었다(Anderson \& Shugan, 1991). 서비스 편의성은 의사결정 편의성, 접근 편의 성, 거래 편의성, 편익 편의성, 사후이익 편의성 등으로 구분 된다(Berry, Seiders, \& Grewal, 2002). 이러한 내용은 서비스 이용자의 활동단계를 반영하는 것이다. 코레일 앱을 대상으로 한 Seo and $\operatorname{Kim}(2013)$ 의 연구에서 이러한 편의성이 고객만족 도와 관계가 있는 것으로 나타났고, 쇼핑몰 앱을 대상으로 한 Chun and $\operatorname{Lim}(2012)$ 의 연구에서도 편의성이 고객만족에 영향 을 주는 것으로 나타났다. 또한 앱 관련 서비스 품질 선행연구 에서 Lee and Lee(2015), Zhang(2018) 등이 편의성 또는 그 와 유사한 개념을 서비스 품질을 측정하기 위한 요인으로 선 정한 바 있다.

\subsection{5. 디자인}

앱의 디자인은 단순히 미적인 부분으로 생각할수 있지만, 앱의 UI와 관련지어 기능적으로도 디자인 요소를 살펴보는 연 구들(Kang, 2011; Park \& Park, 2011; Yu \& Kim, 2015; Feng \& Lee, 2016; Yoon, Choi, \& Kim, 2017; Park, 2018)이 있었 고, 앱의 디자인적 요소가 이용자의 만족도에 영향을 미친다는 연구(Chun \& Lim, 2012)도 존재한다. 앱 관련 서비스 품질 선 행연구에서 Lee와 Lee(2015), Jeon et al.(2016), Shon and Park(2013) 등이 디자인을 서비스 품질을 측정하기 위한 요인 으로 선정한 바 있다.

\subsection{6. 보안성}

선행연구에 따르면 오픈 마켓 앱에서 개인정보유출보호, 안 전한 거래 등이 만족도에 가장 큰 영향을 미치고 있는 것으로 나타났고(Park \& Lee, 2008), 소비자들이 제품을 구매하지 않 은 주요원인에도 보안에 대한 불신과 프라이버시가 가장 중요 한 요인인 것으로 나타났다(Novak \& Hoffman, 2000). 또한 앱 관련 서비스 품질 선행연구에서 Zhang(2018), Chun and Lim (2012) 등이 보안성을 서비스 품질을 측정하기 위한 요인으로 선정하였다

\subsection{7. 고객서비스}

여기서 말하는 고객서비스란 포괄적인 개념의 서비스가 아
닌 고객지원서비스의 개념으로써, 고객이 상품 구매 후 혹은 구매과정에서 고객의 문제 혹은 염려를 해결하고 피드백을 제 공받는 과정을 말한다(Joseph \& Stone, 2003). 이는 사후지원 이나 배송서비스 등을 포함하며 Lee, Kwon, and Kwon(2010) 에 의하면 오픈 마켓의 $\mathrm{ASS}$ 의 편의성은 고객만족에 영향을 준 다. 앱 관련 서비스 품질 선행연구에서 Lee와 Lee(2015), Lee et al.(2017), Chun and Lim(2012), Hwang and Lee(2018) 등 이 고객서비스를 서비스 품질을 측정하기 위한 요인으로 선정 한 바 있다.

\section{2. 카노모형}

카노모형(Kano model)은 일본의 학자인 카노 노리아키에 의해 만들어진 이론으로써, 그는 품질 이론에 대한 연구를 통 해 기존의 일원적 품질인식방법을 대체할 이원적 품질인식방 법의 필요성을 확인하고, 만족과 불만족이라는 주관적 측면, 물리적 충족과 불충족의 객관적 측면을 고려하여 카노모형을 만들었다(Kano, Seraku, Takahashi, \& Tsuji, 1984).

카노모형에 의하면 품질요소들은 매력적 품질요소, 일원적 품질요소, 당연적 품질요소, 무관심 품질요소, 역품질요소 등 5 가지로 구분된다(Kano et al., 1984; Kim, 2010). 이를 구분하 기 위해 설문조사를 실시하는데, 설문 문항들은 각 품질요소에 대한 5 가지의 선택지를 가진 긍정적 질문과 부정적 질문이 쌍 을 이루어 이들의 $5^{\star} 5=25$ 가지 응답 조합에 따라 품질요소가 분류되게 된다<Table $1>$.

Table 1 : Kano evaluation table

\begin{tabular}{|c|c|c|c|c|c|c|}
\hline \multicolumn{2}{|c|}{} & \multicolumn{5}{|c|}{ Answers negative questions } \\
\cline { 2 - 7 } & like & must be & neutral & live with & dislike \\
\hline \multirow{4}{*}{$\begin{array}{c}\text { Answering } \\
\text { positive } \\
\text { questions }\end{array}$} & like & $\mathrm{Q}$ & $\mathrm{A}$ & $\mathrm{A}$ & $\mathrm{A}$ & $\mathrm{O}$ \\
\cline { 2 - 7 } & must be & $\mathrm{R}$ & $\mathrm{I}$ & $\mathrm{I}$ & $\mathrm{I}$ & $\mathrm{M}$ \\
\cline { 2 - 7 } & neutral & $\mathrm{R}$ & $\mathrm{I}$ & $\mathrm{I}$ & $\mathrm{I}$ & $\mathrm{M}$ \\
\cline { 2 - 7 } & live with & $\mathrm{R}$ & $\mathrm{I}$ & $\mathrm{I}$ & $\mathrm{I}$ & $\mathrm{M}$ \\
\cline { 2 - 7 } & dislike & $\mathrm{R}$ & $\mathrm{R}$ & $\mathrm{R}$ & $\mathrm{R}$ & $\mathrm{Q}$ \\
\hline
\end{tabular}

A는 매력적(Attractive) 품질요소이다. 긍정적 질문에 대해 '마음에 든다'로 응답함으로써 충족될 경우 만족을 일으키지만, 부정적 질문에 대해서는 '당연하다', '아무런 느낌이 없다', '하 는 수 없다' 등의 반응을 보이지 않는 응답으로 불충분해도 불 만을 일으키지 않는다.

O는 일원적(One dimensional) 품질요소이다. 긍정적 질문에 대해 '마음에 든다'로 응답함으로써 충족될 경우 만족을 일으 키고, 부정적 질문에 대해 '마음에 안든다'로 응답함으로써 불 충분할 경우 불만도 일으킨다.

$\mathrm{M}$ 은 당연적(Must be) 품질요소이다. 긍정적 질문에 대해 반 응으로 나타나지 않는 응답으로 특별한 반응이 없지만, 부정적 질문에 대해 '마음에 안든다'로 응답함으로써 불충분할 경우 불만을 일으킨다.

I는 무관심(Indifferent) 품질요소이다. 긍정적 질문과 부정적 질문 모두에 반응으로 나타나지 않는 응답으로 충족여부에 무 관하게 반응을 일으키지 않는다.

$\mathrm{R}$ 은 역(Reverse) 품질요소이다. 이는 충족될 경우 불만을 일으킬 수도 있고, 불충분하더라도 만족을 일으킬 수 있다.

마지막으로 5 가지 품질요소에 속하지 않는 $\mathrm{Q}$ 는 응답의 모 
순(Questionable result)을 의미한다. 긍정적 질문과 부정적 질 문 모두에 '마음에 든다' 또는 '마음에 안든다'로 동일하게 응답하 였기 때문에 응답자가 제대로 응답하지 않았을 가능성이 높다.

이상의 분류와 같이 응답자마다 각 품질 요인에 대한 분류 결과가 나오게 되고, 해당 품질 요인에서 가장 많이 나타난 품 질요소가 최종적인 품질특성이 된다.

하지만 카노모형은 두 가지의 한계점을 가지고 있는데, 품 질요소 분류에서 가장 많은 응답자가 나온 요소를 품질특성으 로 결정하므로 세부적 차이를 반영할 수 없다(Kim, 2010; Lee et al., 2017). 또한 결정된 품질요소를 고객이 어떻게 어느 정 도로 받아들이는지 파악할 수 없어 고객만족 개선을 위한 방 안마련에 한계가 있다(Timko, 1993).

\section{3. 고객만족계수}

카노모형의 한계를 보완하기 위해 Timko(1993)는 동일한 품질요소로 분류되더라도 해당 분류내에서 만족과 불만족에 미치는 차이를 구분할 수 있도록 고객만족계수를 제안하였다. 고객만족계수는 고객이 상품의 품질 요인을 접했을 때 만족과 불만족이 어느 정도 나타날 수 있는지 파악한 계수이다(Timko, 1993). 고객만족계수를 산출하기 위해 카노모형의 분석결과를 활용하게 되는데, 물리적 내용이 충족되었을 때 만족의 크기에 영향을 미치는 매력적 품질과 일원적 품질을 더하고 이를 고객 의 품질형태에 많은 영향을 미치는 매력적 품질, 일원적 품질, 당연적 품질, 무관심 품질을 합한 값으로 나누어 정규화하였다 (Lim \& Park, 2010). 불만족계수를 산정하기 위하여 만족계수와 같이 분모는 동일하게 사용하였으며 불만족에 영향을 미치는 일원적 품질과 당연적 품질의 합을 분자로 계산한 후 음의 값 을 취한 값으로 불만족계수를 계산하였다(Timko, 1993). 이에
따라 만족계수와 불만족 계수의 공식을 정리하면 다음과 같다.

만족계수 $=(\mathrm{A}$ 빈도 $+\mathrm{O}$ 빈도 $) /(\mathrm{A}$ 빈도 $+\mathrm{O}$ 빈도 $+\mathrm{M}$ 빈도+|빈도 $)$

불만족계수 $=(\mathrm{O}$ 빈도 $+\mathrm{M}$ 빈도 $/ \mathrm{A}$ 빈도 $+\mathrm{O}$ 빈도 $+\mathrm{M}$ 빈도+|빈도 $)(-1)$

공식을 세부적으로 살펴보면, 만족계수는 0 1의 범위로 산 출된다는 것을 알 수 있으며, 분모로는 충족될 경우 반응이 없 거나(M, I) 만족을 일으키는(A, O) 품질요소를, 분자로는 충족 될 경우 만족을 일으키는 $(\mathrm{A}, \mathrm{O})$ 품질요소를 사용하였다. 즉, 만족계수란 다음과 같은 형태로 산출되며, 충족될 경우 만족을 일으키는 비율이라는 것을 확인할 수 있다.

만족계수 $=$ 만족/(만족+반응없음)

불만족계수는 $-1 \sim 0$ 의 범위로 산출된다는 것을 알 수 있으 며, 분모로는 만족계수와 동일한 vna질요소 분류를 사용하지 만 충족을 기준으로 하지 않고 불충분을 기준으로 하므로 해 석은 다소 달라진다. 분모로는 불충분한 경우 반응이 없거나 $(\mathrm{A}, \mathrm{I})$ 불만을 일으키는 $(\mathrm{O}, \mathrm{M})$ 품질요소를, 분자로는 불충분할 경우 불만을 일으키는 $(\mathrm{O}, \mathrm{M})$ 품질요소를 사용하였다. 즉, 불만 족계수란 다음과 같은 형태로 산출되며, 불충분할 경우 불만을 일으키는 비율이라는 것을 확인할 수 있다.

\section{불만족계수 $=$ 불만/(불만+반응없음)(-1)}

본 연구에서는 이를 통해 온라인 쇼핑몰 앱의 품질 요인들 을 분류하고 해당 품질 요인이 어느 정도의 만족과 불만족을 일으킬 수 있는지 파악하고자 한다.

Table 2: Questionnaire contents

\begin{tabular}{|c|c|c|c|c|}
\hline \multirow{2}{*}{ Factors } & \multirow{2}{*}{ Items } & \multicolumn{2}{|c|}{ Num. of item } & \multirow{2}{*}{ References } \\
\hline & & Positive & Negative & \\
\hline Information & $\begin{array}{l}\text { an exaggeration of info. sufficient app info. } \\
\text { Q\&A, Review, Accuracy of Info., Reliability of Info., } \\
\text { Appropriateness of Info., Relevance of Info., understanding of Info. }\end{array}$ & 8 & 8 & $\begin{array}{l}\text { Shon \& Park(2013), } \\
\text { Lee, Seo, \& Song(2016), Han(2016), } \\
\text { Jeon, Kim, \& Jeong(2016) }\end{array}$ \\
\hline Reliability & $\begin{array}{l}\text { Good impression, Customization, Privacy } \\
\text { Reliability of Service }\end{array}$ & 4 & 4 & $\begin{array}{l}\text { Shon \& Park(2013), Han(2016), } \\
\text { Jeon et al.(2016), }\end{array}$ \\
\hline $\begin{array}{c}\text { Instant } \\
\text { Connectivity }\end{array}$ & $\begin{array}{l}\text { Instant connection, on-line searching, response velocity of menu, } \\
\text { response velocity of output, Access velocity, Connectivity, Mobility, } \\
\text { Place }\end{array}$ & 8 & 8 & $\begin{array}{l}\text { Chun \& Lim(2012), Kim(2012), } \\
\text { Shin \& Kim(2013), Kang(2014), } \\
\text { Lee \& Lee(2015), Zhang(2018) }\end{array}$ \\
\hline Convenience & $\begin{array}{l}\text { easy of learning how to use, Access goods info., various payment } \\
\text { methods, easy of composition }\end{array}$ & 5 & 5 & $\begin{array}{c}\text { Anderson \& Shugan(1991), } \\
\text { Berry et al.(2002), } \\
\text { Seo, Chun, \& Lim(2012), Kim(2013), } \\
\text { Lee \& Lee(2015), Zhang(2018) }\end{array}$ \\
\hline Design & $\begin{array}{l}\text { Attractive design, Harmonious design, excellent graphics design, } \\
\text { layout of letter \& picture, color arrangement, visual effects }\end{array}$ & 6 & 6 & $\begin{array}{l}\text { Kang(2011), Park \& Park(2011), } \\
\text { Yu \& Kim(2015), Feng \& Lee(2016), } \\
\text { Yoon et al.(2017), Park(2018) }\end{array}$ \\
\hline Security & $\begin{array}{l}\text { Transaction info Security, Payment methods stability, Privacy, } \\
\text { Preventing usage history }\end{array}$ & 4 & 4 & $\begin{array}{l}\text { Novak \& Hoffman(2000), } \\
\text { Chun \& Lim(2012), Zhang(2018) }\end{array}$ \\
\hline $\begin{array}{l}\text { Customer } \\
\text { Service }\end{array}$ & $\begin{array}{l}\text { AS reliability, Clearance of compensation regulations, quick } \\
\text { delivery }\end{array}$ & 3 & 3 & $\begin{array}{l}\text { Joseph \& Stone(2003), } \\
\text { Lee et al.(2010), Chun \& Lim(2012), } \\
\text { Lee \& Lee(2015), Lee et al.(2017), }\end{array}$ \\
\hline
\end{tabular}


Table 3: General Characteristics of Sample

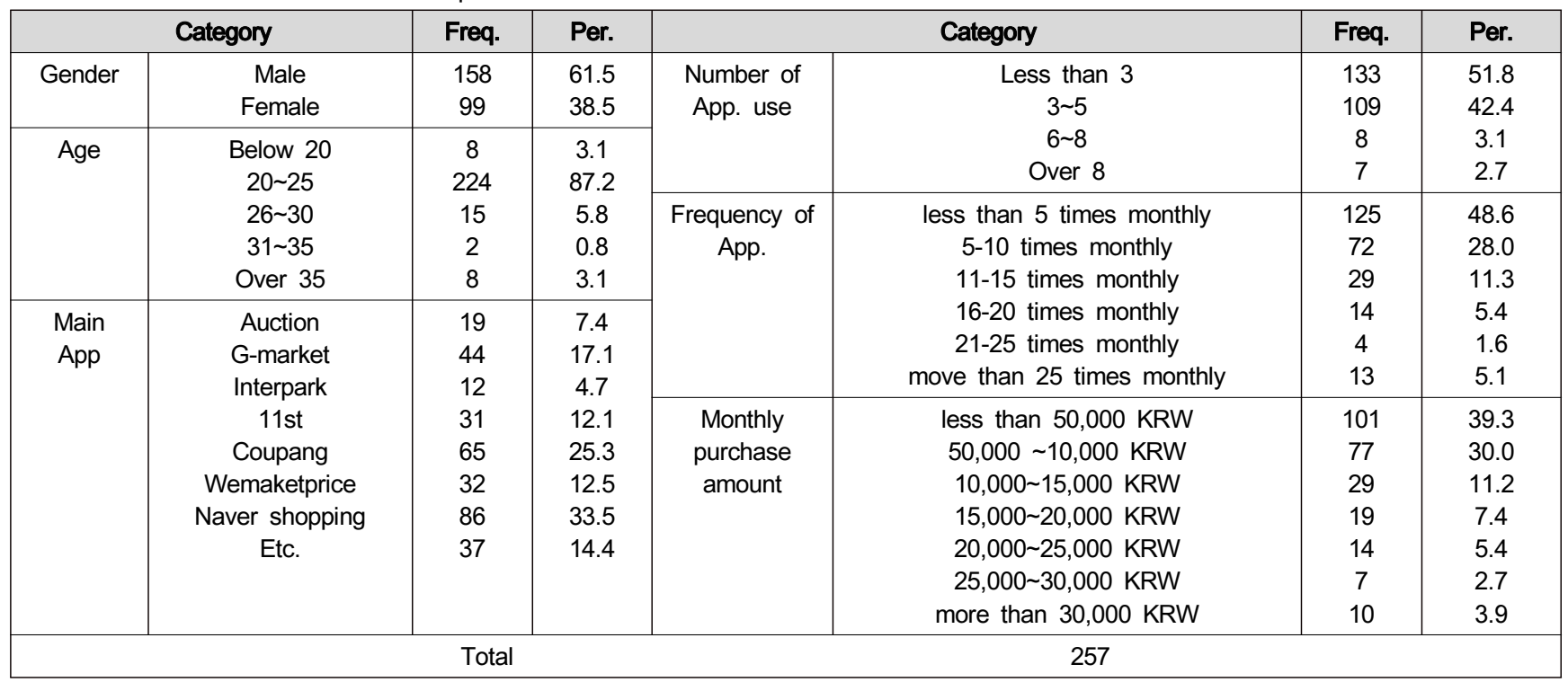

\section{3. 연구설계}

\section{1. 연구방법 및 연구설계}

본 연구에서는 카노 모형을 활용하였으며, 온라인 쇼핑몰과 앱 품질 관련연구를 통해 정보성, 신뢰성, 즉시연결성, 편의성, 디자인, 보안성 및 고객서비스 등 7 개의 품질차원에서 30 개의 하위 변수로 설정하였다.

특히, 모바일 쇼핑 앱 품질 측정을 위해 구성한 설문 문항 은 $\mathrm{Kano}$ 가 제안한 긍정적 질문과 부정적 질문을 동시에 물어 보는 형식을 사용하였다. 예를들어, '앱 정보의 충분성' 항목의 경우, '앱에서 제공되는 정보가 충분하다면 어떤 느낌이 들겠 습니까?'의 긍정형 질문과 반대로 '앱에서의 제공되는 정보가 충분하지 않다면 어떤 느낌이 들겠습니까?’의 부정형 질문을 구성하고, 이에 대하여 (1) 마음에 든다, (2) 당연하다, (3) 아 무 느낌이 없다, (4) 하는 수 없다, (5) 마음에 안든다로 응답 항목을 구성하였다.

Kano 모형의 한계점으로 이원적 질문으로 인해 설문 문항 수가 많아 응답자에게 혼란을 초래할 수 있다는 단점을 보완 하고, 응답자의 일관성 유지 동기를 고려하여, 동일방법 편의 를 줄이기 위해 긍정 질문 및 부정 질문 긍정 질문과 부정적 질문 항목을 구분하여 구성하였다(Podsakoff, MacKenzie, Lee, \& Podsakoff, 2003; Ko, 2013).

\section{2. 자료수집방법}

본 연구에서는 Kanno가 제안한 이원적 품질을 측정하기 위 하여 국내 모바일 기기를 이용해 쇼핑 경험을 가진 고객을 대 상으로 하였다. 구조화된 설문지를 통해 자료수집이 이루어졌 으며, 조사기간은 2018년 10월부터 약 1주간 진행되었다. 수 집된 설문지 총 260 부 중 항목누락으로 3 부를 제외한 257 부 가 분석에 사용되었다.

\section{4. 실증분석}

\section{1. 표본의 특성}

표본의 인구통계학적 특성과 쇼핑몰 앱 이용 특성은 다음과 같다.인구통계학적 특성은 다음과 같다. 성별의 경우 남성이 158 명(61.5\%), 여성이 99명(38.5\%)으로 남성이 많았다. 연령 의 경우 20 25세가 224명(87.2\%)로 대부분이었고, 26 30세 15 명(5.8\%), 20세 미만과 35 세 이상이 각각 8 명(3.1\%), 30 세 35세 2명(0.8\%) 순으로 나타났다.

쇼핑몰 앱 이용 특성은 다음과 같다. 주로 사용하는 쇼핑몰 앱의 경우 네이버 쇼핑 이용자가 86 명(33.5\%)으로 가장 많았 고, 쿠팡 65명(25.3\%), $\mathrm{G}$ 마켓 44 명(17.1\%), 위메프 32명 (12.5\%), 11번가 31명(12.1\%), 옥션 19명(7.4\%), 인터파크 12 명 $(4.7 \%)$ 순으로 나타났다. 사용하는 쇼핑몰 앱의 숫자는 2개 이하 이용자가 133 명(51.8\%)으로 가장 많았고 3 5개 109명 (42.4\%), 6 8개(3.1\%), 9개 이상 7명(2.7\%) 순으로 나타났다. 쇼핑몰 앱 이용빈도는 월 5 회 미만이 125 명(48.6\%)으로 가장 많았고, 월 5 10회 72명(28.0\%), 월 11 15회 29명(11.3\%), 월 16 20회 14명(5.4\%), 월 30회 이상 13명(5.1\%), 월 25 30회 4명(1.6\%) 순으로 나타났다. 쇼핑몰 앱을 이용한 월 구매액은 5 만원 미만이 101 명(39.3\%)으로 가장 많았고, 5 10만원 미만 77명(30.0\%), 10 15만원 미만 29명(11.2\%), 15 20만원 미만 19 명(7.4\%), 20 25만원 미만 14명(5.4\%), 30만원 이상 10명 (3.9\%), 25 30만원 미만 7명(2.7\%) 순으로 나타났다.

\section{2. 쇼핑몰 앱 서비스 속성 분류}

\subsection{1. 카노모형을 활용한 분류}

카노모형의 서비스 속성 분류에 따라, 각 서비스 품질 속성 들은 해당 서비스에 대한 긍정적 질문과 부정적 질문을 조합 
하여 매력적 $(\mathrm{A})$, 일원적 $(\mathrm{O})$, 당연적 $(\mathrm{M})$, 무관심(I), 역품질 $(\mathrm{R})$ 로 분류된다. 본 연구에서 조사된 쇼핑몰 앱 서비스 품질 요소의 경우 매력적 품질요소 6 개, 일원적 품질요소 29 개, 무관심 품 질요소 1 개, 역품질요소 1 개로 분류되었다<Table 4>.

정보성과 관련된 문항들은 대부분 일원적 품질요소로 분류 되었으나, 정보의 과장의 경우 역품질요소로 분류되었고, 관련 정보 제공은 무관심 품질요소로 분류되었다. 즉, 대체로 쇼핑 몰 앱의 정보성이 제공된다면 이용자들의 만족을, 제공되지 않 는다면 불만족을 일으키지만, 과장된 정보가 제공될 경우에는 오히려 불만족을 일으키며, 과장된 정보가 없다면 만족을 일으 킨다. 또한 관련정보 제공으로 인한 만족이나 불만족은 나타나 지 않을 것이다.

신뢰성과 관련된 문항들은 모두 일원적 품질요소로 분류되 었다. 즉, 이용자가 좋은 인상을 느끼고, 맞춤서비스를 제공받
으며, 개인정보가 잘 보호되고, 서비스에 신뢰가 간다면 만족 을 일으키며 반대의 경우에는 불만족을 일으킨다.

즉시연결성과 관련된 문항들은 모두 일원적 품질요소로 분 류되었다. 즉, 앱이 즉시 연결되고, 실시간으로 검색되며, 메뉴 의 속도가 빠르고, 앱의 응답속도가 빠르며, 접속속도가 빠르 면서, 쇼핑몰 앱이 연결이 잘되고, 이동중에서 연결품질이 좋 으며, 장소에 관계없이 연결품질이 좋다면 만족을 일으키며 반 대의 경우에는 불만족을 일으킨다.

편의성과 관련된 문항들은 모두 일원적 품질요소로 분류되 었다. 즉, 쇼핑몰 앱의 이용방법을 익히기 쉽고, 상품정보에 대한 접근성이 좋으며, 결제방법이 다양하고, 앱의 구성을 이 해하기 쉽다면 만족을 일으키며 반대의 경우에는 불만족을 일 으킨다.

Table 4: Classifications of Shopping App attributes

\begin{tabular}{|c|c|c|c|c|c|c|c|c|c|c|}
\hline \multirow{2}{*}{ Factors } & \multirow{2}{*}{ Items } & \multicolumn{6}{|c|}{ Quality Component } & \multirow{2}{*}{ KANO } & \multirow{2}{*}{ SI } & \multirow{2}{*}{ DSI } \\
\hline & & A & $M$ & 0 & 1 & $\mathbf{R}$ & $\mathbf{Q}$ & & & \\
\hline \multirow{8}{*}{ Information } & an exaggeration of info. & 3 & 3 & 3 & 68 & 179 & 1 & $\mathrm{R}$ & 0.08 & -0.08 \\
\hline & sufficient app info. & 47 & 46 & 110 & 47 & 3 & 4 & $\mathrm{O}$ & 0.63 & -0.62 \\
\hline & Q\&A, Review & 38 & 50 & 94 & 66 & 5 & 4 & $\mathrm{O}$ & 0.53 & -0.58 \\
\hline & Accuracy of Info. & 28 & 53 & 138 & 36 & 1 & 1 & $\mathrm{O}$ & 0.65 & -0.75 \\
\hline & Reliability of Info. & 33 & 35 & 150 & 36 & 3 & 0 & $\mathrm{O}$ & 0.72 & -0.73 \\
\hline & Appropriateness of Info & 28 & 35 & 111 & 78 & 3 & 2 & $\mathrm{O}$ & 0.55 & -0.58 \\
\hline & Relevance of Info. & 54 & 37 & 71 & 89 & 5 & 1 & 1 & 0.50 & -0.43 \\
\hline & understanding of Info. & 67 & 23 & 116 & 47 & 1 & 3 & $\mathrm{O}$ & 0.72 & -0.55 \\
\hline \multirow{4}{*}{ Reliability } & Good impression & 40 & 10 & 172 & 34 & 0 & 1 & $\mathrm{O}$ & 0.83 & -0.71 \\
\hline & Customization & 83 & 10 & 106 & 53 & 1 & 4 & $\mathrm{O}$ & 0.75 & -0.46 \\
\hline & Privacy & 10 & 70 & 155 & 21 & 0 & 1 & $\mathrm{O}$ & 0.64 & -0.88 \\
\hline & Reliability of Service & 25 & 68 & 131 & 32 & 1 & 0 & $\mathrm{O}$ & 0.61 & -0.78 \\
\hline \multirow{8}{*}{$\begin{array}{c}\text { Instant } \\
\text { Connectivity }\end{array}$} & Instant connection & 58 & 33 & 101 & 60 & 5 & 0 & $\mathrm{O}$ & 0.63 & -0.53 \\
\hline & on-line searching & 85 & 28 & 92 & 51 & 1 & 0 & $\mathrm{O}$ & 0.69 & -0.47 \\
\hline & response velocity of menu & 69 & 24 & 117 & 43 & 3 & 1 & $\mathrm{O}$ & 0.74 & -0.56 \\
\hline & response velocity of output & 67 & 23 & 130 & 35 & 2 & 0 & $\mathrm{O}$ & 0.77 & -0.60 \\
\hline & Access velocity & 68 & 30 & 125 & 33 & 1 & 0 & $\mathrm{O}$ & 0.75 & -0.61 \\
\hline & Connectivity & 43 & 42 & 110 & 60 & 1 & 1 & $\mathrm{O}$ & 0.60 & -0.60 \\
\hline & Mobility & 47 & 37 & 85 & 78 & 9 & 1 & $\mathrm{O}$ & 0.53 & -0.49 \\
\hline & Place & 70 & 31 & 104 & 49 & 3 & 0 & $\mathrm{O}$ & 0.69 & -0.53 \\
\hline \multirow{4}{*}{ Convenience } & easy of learning how to use & 69 & 33 & 87 & 64 & 2 & 2 & $\mathrm{O}$ & 0.62 & -0.47 \\
\hline & Access goods info. & 67 & 24 & 120 & 45 & 0 & 1 & $\mathrm{O}$ & 0.73 & -0.56 \\
\hline & various payment methods & 67 & 34 & 80 & 72 & 3 & 1 & $\mathrm{O}$ & 0.58 & -0.45 \\
\hline & easy of composition & 60 & 27 & 97 & 68 & 5 & 0 & $\mathrm{O}$ & 0.62 & -0.49 \\
\hline \multirow{6}{*}{ Design } & Attractive design & 100 & 8 & 73 & 73 & 2 & 1 & A & 0.68 & -0.32 \\
\hline & Harmonious design & 92 & 10 & 68 & 84 & 2 & 1 & A & 0.63 & -0.31 \\
\hline & excellent graphics design & 95 & 9 & 79 & 73 & 1 & 0 & A & 0.68 & -0.34 \\
\hline & layout of letter \& picture & 89 & 13 & 83 & 70 & 2 & 0 & A & 0.67 & -0.38 \\
\hline & color arrangement & 88 & 11 & 73 & 84 & 0 & 1 & A & 0.63 & -0.33 \\
\hline & visual effects & 106 & 9 & 75 & 64 & 1 & 2 & A & 0.71 & -0.33 \\
\hline \multirow{4}{*}{ Security } & Transaction info Security & 16 & 74 & 142 & 25 & 0 & 0 & $\mathrm{O}$ & 0.61 & -0.84 \\
\hline & Payment methods stability & 10 & 74 & 146 & 27 & 0 & 0 & $\mathrm{O}$ & 0.61 & -0.86 \\
\hline & Privacy & 10 & 74 & 148 & 23 & 2 & 0 & $\mathrm{O}$ & 0.62 & -0.87 \\
\hline & Preventing usage history & 17 & 75 & 118 & 37 & 9 & 1 & $\mathrm{O}$ & 0.55 & -0.78 \\
\hline \multirow{3}{*}{$\begin{array}{l}\text { Customer } \\
\text { Service }\end{array}$} & A/S reliability & 43 & 41 & 138 & 35 & 0 & 0 & $\mathrm{O}$ & 0.70 & -0.70 \\
\hline & Clearance of compensation regulations & 24 & 62 & 138 & 31 & 2 & 0 & $\mathrm{O}$ & 0.64 & -0.78 \\
\hline & quick delivery & 76 & 26 & 119 & 35 & 1 & 0 & $\mathrm{O}$ & 0.76 & -0.57 \\
\hline
\end{tabular}


Table 5: Results of m-shopping mall quality with Kano Model

\begin{tabular}{|c|c|c|c|c|}
\hline KANO & Items & Quality Factor & SI & DSI \\
\hline \multirow{6}{*}{ Attractive Quality } & DS1 & Design & 0.68 & -0.32 \\
\hline & DS2 & Design & 0.63 & -0.31 \\
\hline & DS3 & Design & 0.68 & -0.34 \\
\hline & DS4 & Design & 0.67 & -0.38 \\
\hline & DS5 & Design & 0.63 & -0.33 \\
\hline & DS6 & Design & 0.71 & -0.33 \\
\hline Indifferent Quality & Inf7 & Information & 0.5 & -0.43 \\
\hline \multirow{29}{*}{ One dimensional } & Inf2 & Information & 0.63 & -0.62 \\
\hline & Inf3 & Information & 0.53 & -0.58 \\
\hline & Inf4 & Information & 0.65 & -0.75 \\
\hline & Inf5 & Information & 0.72 & -0.73 \\
\hline & Inf6 & Information & 0.55 & -0.58 \\
\hline & Inf8 & Information & 0.72 & -0.55 \\
\hline & Rel1 & Reliability & 0.83 & -0.71 \\
\hline & Rel2 & Reliability & 0.75 & -0.46 \\
\hline & Rel3 & Reliability & 0.64 & -0.88 \\
\hline & Rel4 & Reliability & 0.61 & -0.78 \\
\hline & IC1 & Instant Connectivity & 0.63 & -0.53 \\
\hline & IC2 & Instant Connectivity & 0.69 & -0.47 \\
\hline & IC3 & Instant Connectivity & 0.74 & -0.56 \\
\hline & IC4 & Instant Connectivity & 0.77 & -0.6 \\
\hline & IC5 & Instant Connectivity & 0.75 & -0.61 \\
\hline & IC6 & Instant Connectivity & 0.6 & -0.6 \\
\hline & IC7 & Instant Connectivity & 0.53 & -0.49 \\
\hline & IC8 & Instant Connectivity & 0.69 & -0.53 \\
\hline & CV1 & Convenience & 0.62 & -0.47 \\
\hline & CV2 & Convenience & 0.73 & -0.56 \\
\hline & CV3 & Convenience & 0.58 & -0.45 \\
\hline & CV4 & Convenience & 0.62 & -0.49 \\
\hline & SC1 & Security & 0.61 & -0.84 \\
\hline & SC2 & Security & 0.61 & -0.86 \\
\hline & SC3 & Security & 0.62 & -0.87 \\
\hline & SC4 & Security & 0.55 & -0.78 \\
\hline & CS1 & Customer Service & 0.7 & -0.7 \\
\hline & CS2 & Customer Service & 0.64 & -0.78 \\
\hline & CS3 & Customer Service & 0.76 & -0.57 \\
\hline Reverse Quality & Inf1 & Information & 0.08 & -0.08 \\
\hline
\end{tabular}

디자인과 관련된 문항들은 모두 매력적 품질요소로 분류되 었다. 즉, 디자인이 매력적이거나, 조화롭거나, 그래픽이 우수 하거나, 글씨와 그림의 배치가 좋거나, 색상이 잘 배열되어 있 거나, 시각적 효과가 좋다면 만족을 일으키지만, 반대의 경우 라도 불만족을 일으키지는 않는다.

보안성과 관련된 문항들은 모두 일원적 품질요소로 분류되 었다. 즉, 거래정보에 대한 보안이 철저하고, 지불방식이 안정 적이며, 개인정보가 보호되고, 사용내역 누출보장성이 있다면 만족을 일으키며 반대의 경우에는 불만족을 일으킨다.

고객서비스와 관련된 문항들은 모두 일원적 품질요소로 분 류되었다. 즉, A/S가 신뢰를 주고, 보상규정이 명확하며, 배송 이 신속하다면 만족을 일으키며 반대의 경우에는 불만족을 일 으킨다.

\subsection{2. 고객만족계수에 따른 분류}

Timko(1993)의 분류방법에 따라 만족계수와 불만족계수의 크기에 따라 각 서비스 속성을 분류하여 제시하면 다음의 <Figure 1>과 같다. 이를 품질차원별로 살펴보면, 다음과 같 다. 정보성의 경우 정보의 과장이 무관심 품질요소에, 관련정 보 제공은 매력적 품질요소에 속했으며 그 외에는 모두 일원 적 품질요소로 분류되었다. 계수의 크기를 살펴보면, 무관심 품질요소인 정보의 과장을 제외하면 만족계수가 0.50 0.72, 불 만족계수가 $-0.41 \sim-0.73$ 으로 나타났다. 즉, 정보성은 대체로 어느 정도의 만족도, 불만족도 일으킬 수 있다. 신뢰성의 경우 맞춤서비스 제공은 매력적 품질요소에, 그 외에는 모두 일원적 품질요소로 분류되었다. 계수의 크기를 살펴보면, 만족계수가 $0.61 \sim 0.83$, 불만족계수가 $-0.46 \sim 0.88$ 로 나타났다. 즉, 신뢰성이 좋을 경우 이용자 만족도 크지만, 반대일 경우 불만족도 클 수 있다. 즉시연결성의 경우 이동 중 연결품질은 매력적 품질요소 에, 그 외에는 모두 일원적 품질요소로 분류되었다. 계수의 크 기를 살펴보면, 만족계수가 0.53 0.77, 불만족계수가 -0.49 0.61 로 나타났다. 즉, 즉시연결성은 대체로 어느 정도의 만족 도, 불만족도 일으킬 수 있다. 편의성의 경우 상품정보 접근 성은 일원적 품질요소에, 그 외에는 모두 매력적 품질요소로 분류되었다. 계수의 크기를 살펴보면, 만족계수가 0.58 0.73,

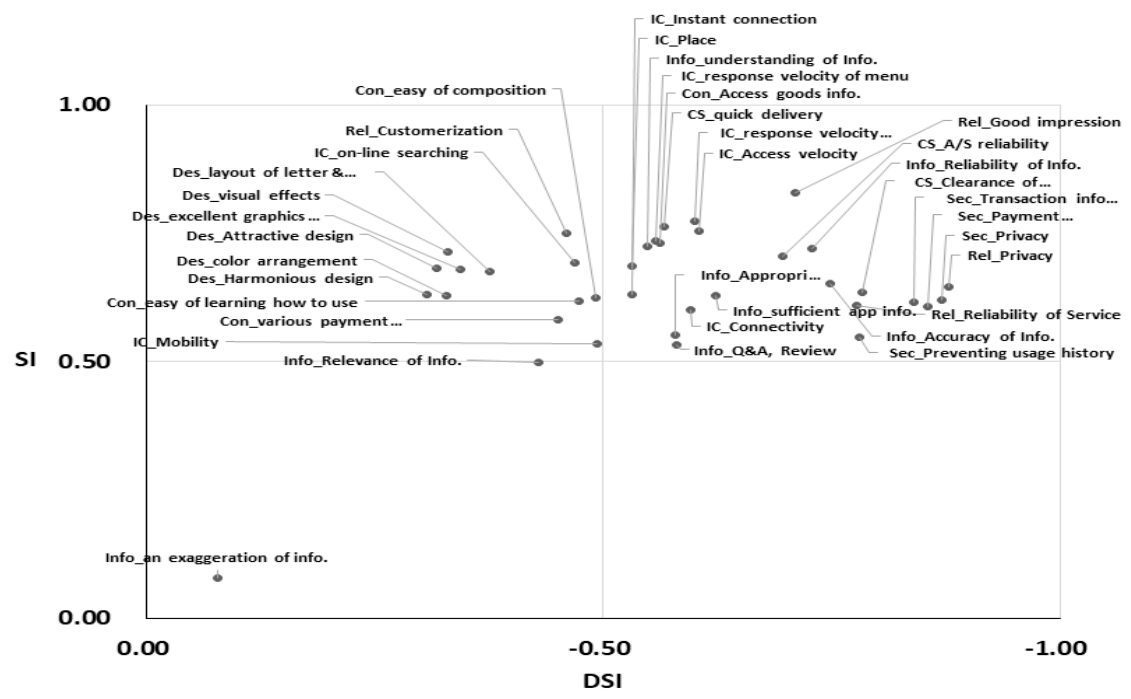

Figure 1: Service quality attribute classification using Customer Satisfaction Coefficient 
불만족계수가 -0.45 -0.49로 나타났다. 즉, 편의성은 대체로 어 느 정도의 만족도, 불만족도 일으킬 수 있지만, 상대적으로 만 족에 미치는 영향이 크다. 디자인의 경우 모두 매력적 품질요 소로 분류되었다. 계수의 크기를 살펴보면, 만족계수가 0.63 0.71, 불만족계수가 $-0.31 \sim-0.38$ 로 나타났다. 즉, 디자인 이 좋은 경우 만족을 일으키지만, 디자인이 좋지 않아도 불만 족은 잘 나타나지 않는다. 보안성의 경우 모두 일원적 품질요 소로 분류되었다. 계수의 크기를 살펴보면, 만족계수가 0.55 0.62 , 불만족계수가 $-0.78 \sim-0.87$ 로 나타났다. 즉, 보안성이 좋 을 경우 어느정도 만족을 일으키지만, 보안성이 나쁘다면 더욱 큰 불만족을 일으킨다. 고객서비스의 경우 모두 일원적 품질요 소로 분류되었다. 계수의 크기를 살펴보면, 만족계수가 0.64 0.76 , 불만족계수가 $-0.57 \sim-0.78$ 로 나타났다. 즉, 고객서비스 는 대체로 어느 정도의 만족도, 불만족도 일으킬 수 있다.

\section{5. 결론}

\section{1. 분설결과 요약 및 해석}

본 연구에서는 카노 모형을 통한 모바일 쇼핑 앱의 서비스 품질 서비스 품질 차원을 분류하고, 각 서비스 품질을 구성하 는 항목에 대하여 이원적 품질차원에 대하여 살펴보았다. 이를 위해 먼저, 기존 선행연구를 서비스 항목에 대한 품질 차원을 정리하였고 이러한 차원들을 카노 모형을 통해 분류하여 결과 를 도출하였다.

연구 결과를 살펴보면, 쇼핑 앱 이용자들은 정보성, 신뢰성, 즉시연결성, 편의성, 고객서비스 등 대부분의 서비스 품질 차 원항목에서 일원적 품질요소로 인지하는 것으로 나타났다. 정 보성의 경우, 대체로 정보성을 높일 수 있는 기능에 대하여 이 용자들은 일원적인 품질지각이 높지만, 과장된 정보에 경우, 고객의 불만족을 가중시킬 수 있으며 관련정보 제공은 오히려 고객에게 제대로 인지되지 못하고 있어, 다양한 정보제공 차원 에서의 접근 관점에서 지향될 수 있는 요소이나, 지나친 정보 제공을 위한 노력은 고객으로부터 인지되기 힘들 수 있을 것 이다. 따라서 제품 및 서비스의 속성과 편익을 직관적으로 판 단할 수 있는 정보 중심의 정보제공이 오히려 고객의 만족도 를 유지 또는 상승시킬 수 있을 것으로 보인다.

신뢰성의 관련된 모든 문항들은 일원적 품질요소로 인지되 었다. 신뢰성 구성항목으로는 앱을 통해 인지되는 좋은 인상, 맞춤서비스 제공, 개인정보 보호 및 서비스 등은 고객의 서비 스 인지가 높을수록 신뢰성을 높일 수 있다. 따라서 앱을 통한 단순한 공지사항이나 상품추천 메시지 등의 단순한 정보 전달 보다는 서비스 개선을 위한 기능 중심의 업데이트 등을 통해 고객에게 지속적으로 앱에 대한 관리 노력에 대한 메시지가 전달될 경우, 고객에게 좋은 인상과 함께 신뢰로 이어질 수 있 을 것으로 보인다.

다음으로 즉시연결성 관련 항목들에서도 모든 항목이 일원 적 품질요소로 분류되었다. 따라서 지나치게 많은 데이터를 필 요로 하는 앱 크기나 업데이트로 인해 접속 지연속도를 유발 하거나 대기시간을 높인다면, 오히려 고객으로 하여금 불만족 을 일으킬 수 있어, 이를 고려한 앱 기능과 설계가 이루어져야 할 것이다. 또한, 이벤트 등 캠페인 시행시, 접속자 수를 고려 하여 이벤트 비참여자 등의 접속의 불안정을 제공하지 않도록
안정적 서버운영을 위한 고려도 함께 이루어져야 할 것이다.

편의성 품질의 항목에서도 모두 일원적 품질요소로 분류되 었다. PC기반의 서비스와의 호환성과 서비스의 기능 평준화를 고려하여 지나치게 다양한 기능의 삽입은 모바일 앱 내에서 항해용이성을 저해할 수 있으며, 결과적으로 사용자의 앱의 이 용에 불편을 초래할 수 있다. 따라서 메뉴의 기능을 단순화하 되, 제공되는 서비스 기능 또는 화면에 적절한 Push방식의 메 뉴제공을 통해, 고객의 이용편의성을 극대화할 수 있는 접근이 요구된다.

디자인 항목은 다른 서비스 품질과 다르게 매력적 품질요소 로 분류되었다. 국내 온라인 쇼핑몰의 서비스 기능은 상품에 대한 정보나 배치, 상품 후기정보, $\mathrm{Q} \& \mathrm{~A}$, 검색 제품 알림서비 스 등 어느 정도 상향평준화되어 있어, 오히려 보편적인 서비 스로의 인지될 가능성이 높아 가격 이외에 차별화 요소로서 서비스 접근이 쉽지 않는 환경을 지니고 있다. 이에 서비스의 차별화 측면에서 앱 디자인에 대한 접근이 하나의 방안이 될 수 있을 것으로 보인다.

보안성 요인에서는 관련 문항들이 모두 일원적 품질요소로 분류되고 있다. 최근 지불거래의 편의성이 강조되면서, 하나의 SNS 아이디를 이용한 다양한 쇼핑몰의 접근 서비스의 등장과 함께 핸드폰, 마일리지, 신용카드에서 각종 Pay 서비스의 제공 등은 이루어지고 있다. 이러한 서비스는 결제 편의성 높일 수 있지만, 지나친 서비스의 확대는 오히려 고객으로 하여금 개인 정보유출에 대한 우려를 자극할 수 있어 불만족사항으로도 연 결될 수 있다. 따라서 보안사고로부터 안전한 관리를 위한 정 책에 대한 홍보나 장치를 통해 고객의 불안요소를 제거할 수 있는 접근이 요구된다.

마지막으로 고객서비스 차원에서도 관련된 모든 문항들이 일원적 품질요소로 분류되었다. 온라인 기반의 서비스는 고객 이 상품을 고를때는 직접 경험하기 어렵고, 제품의 전달 과정 에서 배달지연, 훼손 등 다양한 문제들이 발생할 수 있다. 따 라서 고객의 제품에 대한 간접체험도를 높이기 위해 다양한 매체를 이용한 접근(예: 사진 또는 영상, 체험 커뮤니티 등과의 연동서비스), 고객응대에 있어 모바일이 가지는 기능(예: 위치 정보를 이용한 서비스 접근성 개선) 등 고객서비스에 대한 차 별적인 개선이 이루어진다면, 보다 고객만족도를 높일 수 있을 것으로 보인다.

\section{2. 논의}

이상의 연구결과를 통해 본 연구가 가지는 의의와 함께 관 련 결과를 논의하여 제시하면 다음과 같다. 첫째, 본 연구에서 는 온라인 쇼핑몰 및 모바일 서비스 품질 관련 선행 연구들을 통해 모바일 쇼핑몰 앱에 적용가능한 서비스 품질을 7 개 차원 으로 도출하여 제시하였다. 둘째, 기존 연구에서는 대부분 서 비스 품질을 일차원적으로만 고찰하여, 모든 서비스 요인에 대 한 노력과 시간적 요구나 그 수준에 대한 인지가 어려운 반면, 이를 2차원적으로 제시하면서, 어느 정도 상향 평준화된 전자 쇼핑몰 시장에서 서비스 품질의 차별적인 접근 방향을 제시할 수 있었다. 셋째, Kano 모형을 통해 쇼핑몰 서비스 품질 차원 에서 디자인 차원이 고객에게 하나의 매력적 품질로서 분류되 었으며, 정보품질의 경우, 과대 정보의 역품질, 관련정보제공의 무관심 품질 등의 결과를 도출하였다. 따라서 기술적 구현 및 기능으로만 상향평준화된 차별화가 어려운 온라인 서비스 환 경에서 단순한 브랜드 이미지 개선보다는 고객과의 주요 채널 
에 대한 차별화 요인으로서의 접근가능성을 제시할 수 있을 것으로 보인다. 즉, 이러한 결과는 온라인 쇼핑몰 기업들의 기 본적인 서비스 품질 수준을 유지하기 위한 노력은 지속적으로 이루어져야 함을 보여주며, 보다 중점적으로 관리가 이루어져 야 하는 서비스 품질 차원에 대해 차별적 접근에 대한 방향을 제시할 수 있었다. 이를 통해 모바일 기기로의 이용환경이 변 화하고 있는 시점에, 모바일 쇼핑앱은 더이상 웹사이트의 보완 적 기능으로서가 아닌 고객과의 주요 채널로 인식되어야 하며, 기존 경쟁사와의 경쟁에서 차별적으로 접근할 수 있는 방안으 로 활용될 수 있을 것으로 기대한다.

반면 본 연구에서는 도출된 이원적 서비스 품질 요인이 실 제 소비자의 행동결정요인과의 관계 등 실질적으로 고객의 행 동을 예측하거나 동인으로 작용할 수 있는 요인과의 관계를 검증하지는 못하고 있어, 이에 대한 향후 연구가 필요할 것으 로 보이며, 주요 분석대상이 20 30대 중심으로 이루어지고 있 어, 연구결과를 일반화하는데 제한적 해석이 요구된다.

\section{References}

Akinci, S., Atilgan-Inan, E., \& Aksoy, S. (2010). Re-assessment of ES-Qual and E-RecS-Qual in a pure service setting. Journal of Business Research, 63(3), 232-240.

Anderson, E. W., \& Shugan, S. M. (1991). Repositioning for changing preferences: The case of beef versus poultry. Journal of consumer research, 18(2), 219-232.

Bang, M. S. (2013). The effect of fashion consumers' individual characteristics on mobile shopping acceptance and purchase intension. Master's thesis, Hanyang University.

Berry, L. L., Seiders, K., \& Grewal, D. (2002). Understanding service convenience. Journal of marketing, 66(3), 1-17.

Chun, J. H., \& Lim, Y. W. (2012). E-service quality and behavioral intention in the app shopping mall. Journal of the Korea Academia-Industrial cooperation Society, 13(4), 1609-1618.

Feng, K. Z., \& Lee, H. W. (2016). A Study on Interface Design for Usability Improvements of Korea Tourism Organization App - Based on Chinese Tourists's Usability of "Visit Korea" App -. The Journal of Korean Society of Design Culture, 22(4), 641-655.

Han, J. S. (2016). A study on the effects of the service quality and the usage review characteristics of smartphone and Majib App on satisfaction and reuse intention of Majib App. Culinary Science \& Hospitality Research, 22(2), 234-251.

Hwang, H. J., \& Lee, S. M. (2011), A Study on Transferring the Effects of Brand Reputation and Level of Service Satisfaction of an Offline Channel Company When It is Expanding to an Online Distribution Channel. Journal of Distribution Science, 9(2), 31-36.

Jeon, H. M., Kim, M. J., \& Jeong, H. C. (2016). Influence of smart phone food delivery Apps' service quality on emotional response and App reuse intention-Focused on PAD theory. Culinary Science \& Hospitality Research, 22(2), 206-221.

Jin, G. S., \& Lee, J. H. (2012). Service quality factors affecting satisfaction and repurchase intention of social commerce. The Journal of the Korea Contents Association, 12(3), 311-321.

Joseph, M., \& Stone, G. (2003). An empirical evaluation of US bank customer perceptions of the impact of technology on service delivery in the banking sector. International Journal of Retail \& Distribution Management, 31(4), 190-202.

Kang, M. J. (2011). A Quantitative Analysis of the Satisfaction about Interface Design based on Smartphone Application. The Korean Society of Design Culture, 17(1), 1-9.

Kang, T. C. (2014). How Users' Perceived Ubiquity of Mobile Service Influences on the Satisfaction and the Continuance Usage Intention. Journalism \& Communication, 18(4), 5-34.

Kano, N., Seraku, N., Takahashi, F., \& Tsuji, S. (1984). Attractive quality and must-be quality. Journal of The Japanese Society for Quality Control, 14(2), 147-156.

Kim, D. U., \& Oh, J. S. (2006). A structure on mobile service quality. Journal of the Korea Service Management Society, 7(3), 51-82.

Kim, K. H., \& Yun, S. H. (2012). Deriving the factors to affect the user satisfaction of SNS with a comparison for different service types. The Journal of Internet Electronic Commerce Research, 12(1), 125-143.

Kim, S. S. (2014). Status and Future Tasks of Domestic Mobile Commerce: Focusing on Megastore and Social Commerce. Master's thesis, Kyunghee University.

Kim, S. C. (2010). A Study on the Service Quality Improvement by Kano Model \& Weighted Potential Customer Satisfaction Index. Journal of Distribution Science, 8(4), 19-25.

Kim, Y. C. (2012). Mobile Internet Access and Network Media Utilization. Korean Society For Journalism And Communication Studies Conference Proceedings(May), 63-79.

Kim, Y. L., \& Kim, S. H. (2011). A Study on the Survey of the experts for Development of Mobile Tourism Service Quality Measurement Scales: Focusing on Smartphone's Tourism Service. The Tourism Sciences Society of Korea 35(9), 203-220.

Ko, C. H. (2013). A Structural Approach to Examine the Service Marketing Mix Elements of Airlines Using the Kano Model. Doctorial dissertation, Kyonggi University.

Kwon, S. J., \& Park, S. C. (2015). Perceived Users' Service Quality Model on Mobile Apps -Meditating Effect of Satisfaction. Korea Logistics Review, 25(5), 89-101

Lee, H. C., Kwon, H. I., \& Kwon, J. K. (2010). An Empirical Study on The factors influencing on Customer 
Satisfaction of On-line open Market. Journal of Korean Association of Tax \& Accounting, 27, 167-184.

Lee, M. M., \& Lee, K. C. (2015). Empirical Analysis of the Effects of Service Quality of the Smartphone App Store on UsersRepurchase Intention. Journal of the Korea society of IT services, 14(3), 1-18.

Lee, S. H. (2011). Effects of service quality of Korean telecommunication terminals on Customer satisfaction: Focused on comparison among users of 2G, 3G and smart phone. Department of Business Administration The Graduate School, Catholic University of Daegu.

Lee, T. M., La, S. Y., \& Yeon, S. A. (2009). MOBISQUAL: Dimensionalizing and measuring mobile internet service quality. Journal of Korean Marketing Association, 24(1), 145-179.

Lee, Y. C., Seo, D. H., \& Song, S. H. (2017). Classification and Evaluation of Service Quality Factor s of O2O Delivery Applications Using Kano Model. Journal of Industrial Convergence, 15(2), 27-36.

Lim, S. U., \& Park, Y. T. (2010). Potential customer satisfaction improvement index based on Kano model. Journal of the Korean society for quality management, 38(2), 248-260.

Lu, L., \& Lee, J. H. (2014). The Effect on Flow, Users' Satisfaction and Loyalty by Motivation Factors of Mobile Messenger APP and Quality Factors-Focused on the Comparison between Korean KakaoTalk and Chinese Wechat. The e-Business Studies, 15(3), 255-276.

Novak, T. P., Hoffman, D. L., \& Yung, Y. F. (2000). Measuring the customer experience in online environments: A structural modeling approach. Marketing science, 19(1), 22-42.

Oh, J. C., Yoon, S. J., \& Park, B. I. (2012). A Structural Approach to Examine the Quality Attributes of e-Shopping Malls Using the Kano Model. Asia Pacific Journal of Marketing and Logistics, 24(2), 305-327.

Parasuraman, A., Zeithaml, V. A., \& Berry, L. L. (1988). Servqual: A multiple-item scale for measuring consumer perc. Journal of retailing, 64(1), 12-40.

Parasuraman, A., Zeithaml, V. A., \& Berry, L. L. (1990). Delivering Service. New York, NY: The Free Press.

Parasuraman, A., Zeithaml, V. A., \& Malhotra, A. (2005). ES-QUAL: A multiple-item scale for assessing electronic service quality. Journal of service research, 73), 213-233.

Park, H. J. (2018). Analysis and investigation of Internet of things(IOT) UI Accessibility Design - Focused on loT accessibility design of low vision people -. Journal of Communication Design, 63, 146-159.

Park, J. J., \& Lee, J. H. (2008). A study on internet shopping mall image, satisfaction, and revisit intentionsComparison between meta-mall and open-market. Korean Journal of Human Ecology, 1744), 785-796.

Park, S. H., \& Park, S. H. (2011). App Game Interface for The Core Design Elements Satisfaction Education. Journal of Digital Design, 11(4), 51-59.
Park, Y. J. (2010). The Effects of On-Line Customer's Review on the Purchasing Intention in the Internet Shopping Mall. Master's thesis, Seokyung University.

Podsakoff, P. M., MacKenzie, S. B., Lee, J. Y., \& Podsakoff, N. P. (2003). Common method biases in behavioral research: A critical review of the literature and recommended remedies. Journal of applied psychology, 88(5), 879-903.

Roh, J. G., \& Chung, H. S. (2005). A empirical study on the relationships between the quality factors of mobile internet service and user utilization. Daehan Academy of Management Information Systems, 17, 25-44.

Seo, J. H., \& Kim, Y. T. (2013). Effects of Service Convenience on Customer Satisfaction and Reuse Intention by Korail Talk App Users among Korail Passengers. Journal of the Korean Society for Railway, 16(5), 410-417.

Shin, J. K., \& Lee, S. Y. (2018), The Effects of the Delivery Service Quality of Online Fresh Food Shopping Malls on E-Satisfaction and Repurchase Intention of Online Customers. The East Asian Journal of Business Economics, 6(2), 14-27.

Shin, M. S., \& Kim, H. J. (2013). The Study for IPA(Importance-Performance) of Mobile Commerce Selection Attributes and Service Quality. Management education review, 28(6), 335-355.

Shon, J. G., \& Park, Y. A. (2013). A study on effects of service quality and usage review of smartphone 'majib' application on user satisfaction and reuse intention. Journal of Marketing Studies, 21(3), 1-26.

Siau, K., Lim, E. P., \& Shen, Z. (2001). Mobile commerce: Promises, challenges and research agenda. Journal of Database Management(JDM), 12(3), 4-13.

Timko, M.(1993). An experiment in continuous analysis. Center for Quality of Management Journal, 2(4), 17-20.

Yoon, Y. K., Choi, B. A., \& Kim, S. H. (2017). The design of the visual Interface for Mobile E-commerce App Focused on empirical analysis of Taobao, JD.com, and T-mall -. Journal of Communication Design, 61, 352-362.

Yu, L. L., \& Kim, J. G. (2015). An analysis and study on the app icons design for the silver generation-Focus on the visual elements of icons. Journal of Digital Design, 15(2), 223-232.

Zeithaml, V. A., Parasuraman, A., \& Malhotra, A. (2002). Service quality delivery through web sites: A critical review of extant knowledge. Journal of the academy of marketing science, 30(4), 362-375.

Zhang, X. (2018). The Effect of Information Quality and System Quality on the Satisfaction and Reuse Intention: Focused on Mobile Shopping App. Master's thesis, Gachon University. 